\title{
Evaluation of Asymmetries associated with Class II subdivision malocclusions and Normal occlusion.
}

\author{
Dr. Nazima Jabeen ${ }^{1}$, Dr. Mala Ram Manohar ${ }^{2}$, Dr. G Shivaprakash ${ }^{3}$, \\ Dr. Poorya Naik .D. $S^{4}$ \\ ${ }^{I}$ Assistant Professor, Department of Orthodontics \& Dentofacial Orthodopedics, College of Dental Sciences, \\ Davangere. India. 577004 \\ ${ }^{2}$ Professor, Department of Orthodontics \& Dentofacial Orthodopedics, College of Dental Sciences, Davangere. \\ India. 577004 \\ ${ }^{3}$ Professor and Head, Department of Orthodontics \& Dentofacial Orthodopedics, College of Dental Sciences, \\ Davangere. India. 577004 \\ ${ }^{4}$ Assistant Professor, Department of Orthodontics \& Dentofacial Orthodopedics, College of Dental Sciences, \\ Davangere. India. 577004
}

\begin{abstract}
Aim: The objective of this study was to compare the dental and skeletal asymmetry seen in subjects with Class II subdivision malocclusion and normal occlusion. Materials and Methods: The sample consisted of 30 subjects in each group with Angle Class II subdivision malocclusions and with Angle Class I malocclusions. Postero-Anterior cephalographs were obtained from each subject. The cephalometric measurements were obtained according to the method described by Grummon's and Van de Coppell. Results are expressed as Mean and Standard Deviation. Differences between two groups are compared by unpaired t test. $P=0.05$ or less was considered as statistically significant. Results: Sub-division cases exhibited 10.5\% more asymmetry with angular measurements and exhibited 38\% more asymmetry with linear measurements as compared with normal group. Conclusion: There was a significant amount of radiographic mandibular asymmetry in relation to Class II subdivision malocclusions in general. As a consequence of the more frequent asymmetry in the lower third of face, the mandibular dental midline and the antegonial angle were deviated on the Class II side, as evaluated on the postero-Anterior radiograph.
\end{abstract}

Keywords: Mandibular asymmetry, Postero-Anterior cephalograms, Subdivision malocclusion,

\section{Introduction}

Unilateral Class II cases were classified as subdivision cases by Angle. He reported that a Class II molar relationship developed because of the distal eruption of the mandibular first molars in relation to normally positioned maxillary first molars. Asymmetry in the face and dentition is a naturally occurring phenomenon. Before planning orthodontic treatment to correct subdivision problems, the origin of the asymmetry must be identified. ${ }^{1}$

Symmetry, when applied to facial morphology, refers to the correspondence in size, shape, and location of facial landmarks on the opposite sides of the median sagittal plane. The mandibular asymmetry, also known as the lower third of the face, is important because of its direct effect on facial appearance. Asymmetries of the mandible may cause not only esthetic but also functional problems because of its role in the stomatognathic ${ }^{2}$

Asymmetry in craniofacial areas can be recognized as differences in the size or relationship of the two sides of the face. Asymmetries can be classified according to the structures involved into dental asymmetries, skeletal asymmetries, muscular asymmetries and functional asymmetries. ${ }^{3}$ Class II Subdivision malocclusions are unique in that they display characteristics of both Class I and Class II malocclusions within the same patient. The difference in occlusion between the right and left sides of the dentition presents a challenge for clinicians when attempting to diagnose and treatment plan these malocclusions. The clinician must be able to identify the source of the asymmetry in order to address the primary factor of the malocclusion and achieve an optimal treatment result ${ }^{3,4}$.

A question frequently addressed in the literature is the source of the asymmetry: is it predominantly dentoalveolar, skeletal, or a combination of both? ${ }^{3}$ A question arises as to whether subdivision malocclusions caused by dentoalveolar or skeletal deviations or any compromise treatment plans lead to additional complications, such as tipping of the occlusal plane, dental instability, or temporomandibular disharmonies ${ }^{3,5}$. Alavi et $\mathrm{al}^{5}$ \& Janson et $\mathrm{al}^{16,12}$ suggested that Class II subdivisions result mainly from asymmetry of the mandibular first molars. However, they did not determine whether this was due to dentoalveolar or skeletal asymmetry. Rose et al ${ }^{6}$ reported that the Class II subdivision occurred due to distal positioning of the 
mandibular first molar on the Class II side. Janson et al ${ }^{7}$ concluded that the components that contributed to the asymmetric anteroposterior relationship in the Class II subdivision malocclusion were mainly dentoalveolar, and the primary contributor to the differences between the Class II subdivision malocclusion and the normal occlusion was the distal positioning of the mandibular first molar on the Class II side in mandible without unusual skeletal or positional asymmetries. A secondary contributor was mesial positioning of the maxillary first molar on the Class II side. However, in many Class II subdivision patients, it is possible to discern mild facial asymmetries. ${ }^{4}$ In most casses, the presence and degree of facial asummetry can be diagnosed by using posteroanterior (PA) cephalometry. ${ }^{10,13,14}$

\section{The Objectives Of The Study}

To compare the dental and skeletal asymmetry seen in subjects with Class II subdivision malocclusion and normal occlusion.

\section{Materials And Methods}

Thirty subjects with Class II subdivision malocclusions, (study group) with the selection criterion, all maxillary and mandibular permanent teeth present, complete Class I molar relationship on one side of the dental arch with a full cusp Class II relationship on the other side, no previous orthodontic treatment, no history of facial trauma or medical conditions that could have altered the growth of the apical bases. In control group, 30 subjects with normal occlusion with the same selection criteria, all maxillary and mandibular permanent teeth present, full cusp class I molar relation on both sides, no history of previous orthodontic treatment, no history of facial trauma or medical conditions that could have altered the growth of the apical bases.

Each subjects with class II sub-division malocclusion had apparent facial asymmetry that was evaluated by a facial clinical examination in the frontal view (Fig 1).

The postero-anterior cephalograms were obtained according to Harvold's method. During exposure, the subjects kept their teeth in centric occlusion. (Fig2).

The tracings (Fig 3) of the postero-anterior cephalograms included the following structures: orbits, contours of the nasal cavity, crista galli, zygomatic arches, mandibular contour from one condyle to the other, left and right maxillary contours, lateral aspects of the frontal bone, lateral aspects of the zygomatic bones, maxillary and mandibular central incisors, and maxillary and mandibular first molars.

The cephalometric measurements were obtained according to the method described by Grummons and Van de Coppell ${ }^{9}$, 11. The two forms of this Grummon's analysis- Angular (Fig4) and Linear Measurements ${ }^{14}$. Unpaired Measurements (Fig4a), and Paired Measurements (Fig4b).

For paired structures, the distance to the reference midline was determined for both landmarks, and the difference between the distances was calculated. For unpaired points, the horizontal distance to the midline was determined.

\section{Statistical Analysis}

Results are expressed as Mean and Standard Deviation. Differences between two groups are compared by unpaired t test. $\mathrm{P}=0.05$ or less was considered as statistical significance

Table1. Angular Measurements:

\section{Results}

Table2. Paired Linear measurements:

Table3. Unpaired Linear Measurements:

Sub-division cases exhibited $10.5 \%$ more asymmetry with angular measurements and exhibited $38 \%$ more asymmetry with linear measurements as compared with normal group.

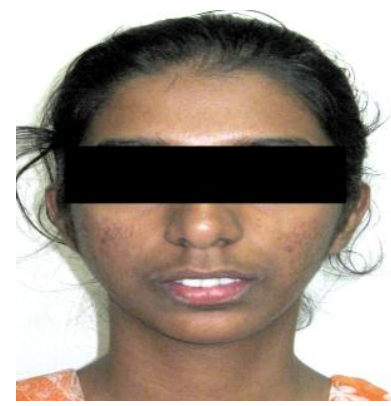

\section{Figures And Tables}

Fig1. Subjects with Class II subdivision malocclusion and apparent facial asymmetry. 


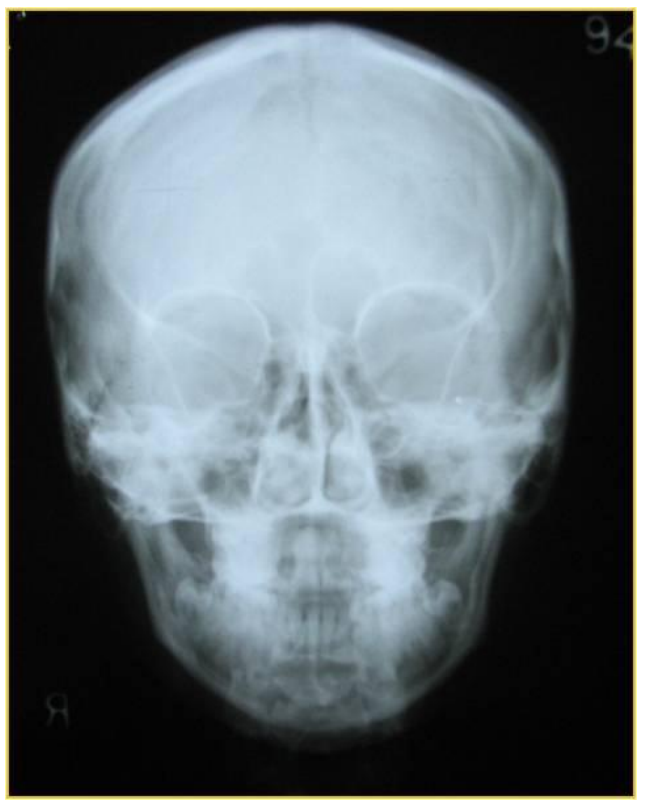

Fig2. Postero-Anterior cephalogram

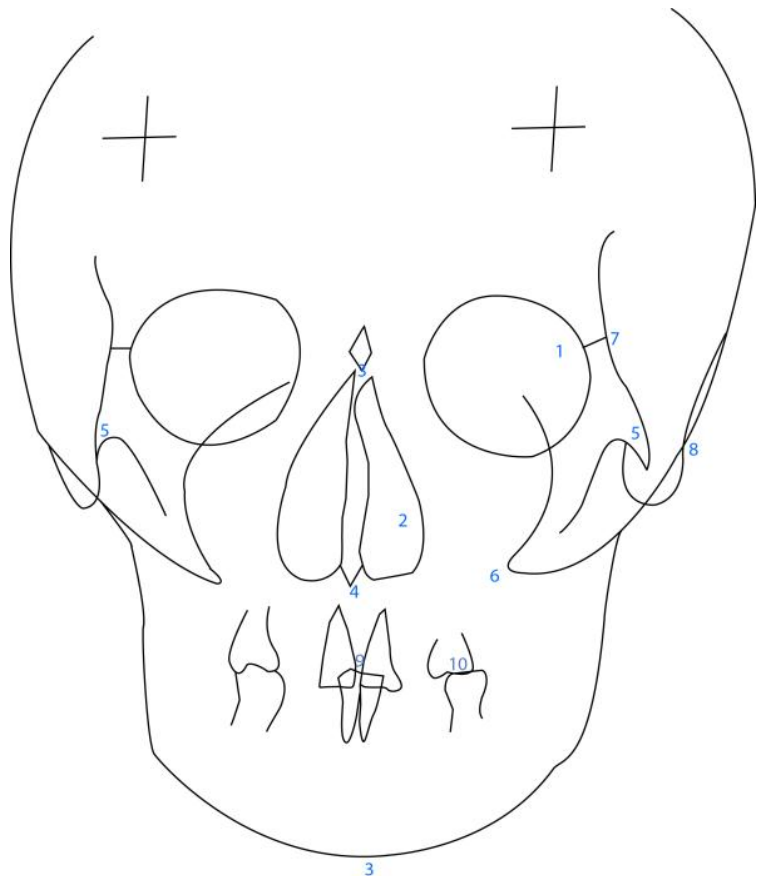

Fig3. Tracings of Postero-Anterior cephalogram

1. Orbits,

2. Contours of the nasal cavity,

3. Crista galli,

4. Anterior nasal spine,

5. Mand. contour from one condyle to the other,

6. Left and right maxillary buttress,

7. Lateral aspects of the frontal bone,

8. Lateral aspects of the zygomatic bones,

9. Max. and mand. Central incisors.

10. Maxillary and mandibular first molars 


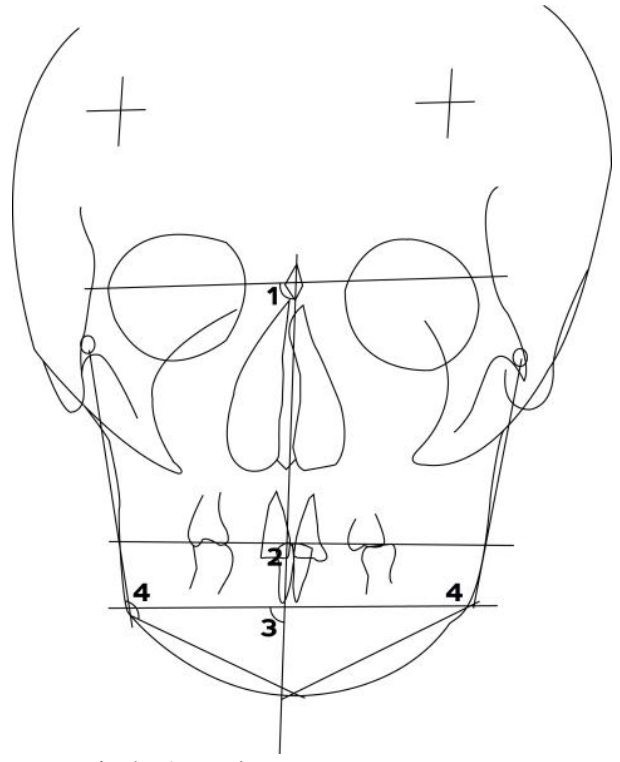

Fig4. Angular Measurements

1. $\mathrm{Z}$ plane angle, angle between $\mathrm{Z}$ plane and $\mathrm{Cg}$-ANS line;

2. Occlusal plane angle, angle between occlusal plane and $\mathrm{Cg}$-ANS line;

3. Antegonial plane angle, angle between antegonial plane and $\mathrm{Cg}-\mathrm{ANS}$ line;

4. Antegonial angle, angle between mandibular ramus and mandibular body;

Linear Measurements

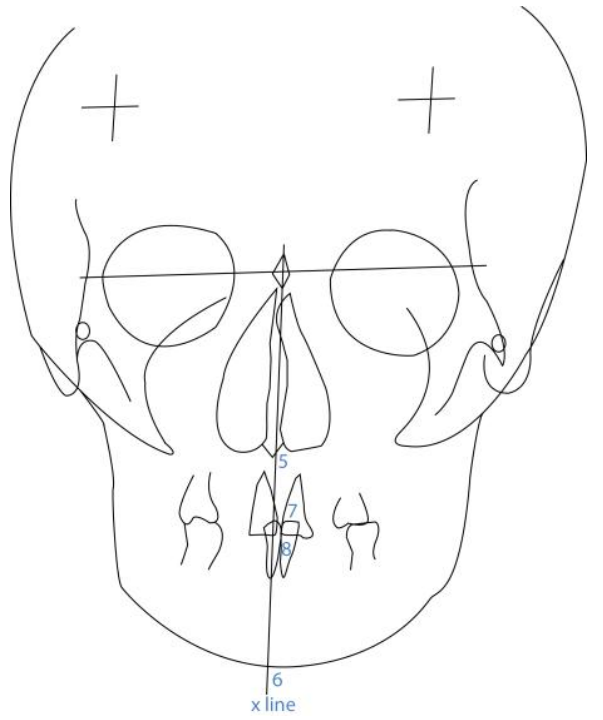

Fig4a. Unpaired Linear Measurements

5. Anterior nasal spine deviation

6. Mandibular deviation

7. Max. dental midline deviation

8. Mandibular mid line deviation 


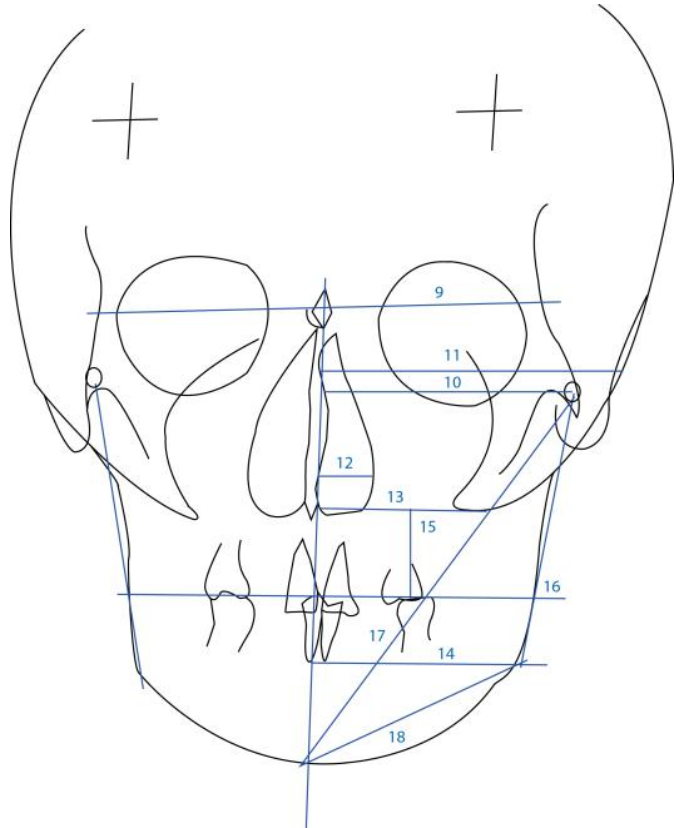

Fig4b. Paired measurements

9. Frontozygomatic suture to X-line dist,

10. Condylion to X-line dist,

11. Zygoma dist,

12. Piriform aperture to $\mathrm{X}$-line dist,

13. Max. buttress to $\mathrm{X}$-line dist,

14. Ante-gonial notch to X-line dist,

15. Max. first molar height,

16. Condylion to antegonial notch dist,

17. Condylion to menton dist,

18. Menton to antigonial notch dist.

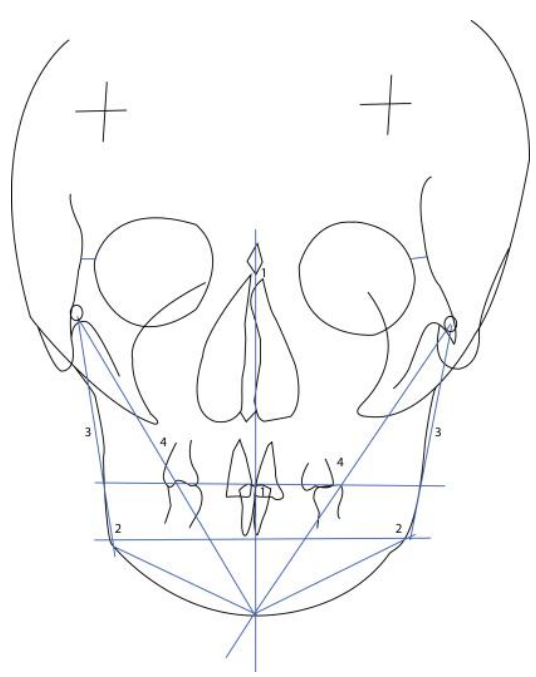

Fig.5. Mandibular asymmetry

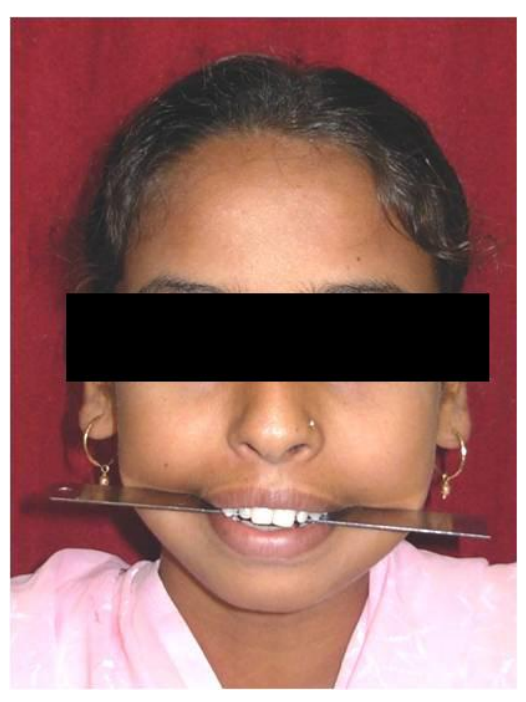

Fig. 6. Occlusal cant

1. Occlusal plane angle

2, Antegonial angle

3 , Condylion to antegonial notch distance

4, Condylion to menton 
Table1. Angular Measurements

\begin{tabular}{|l|r|r|r|r|r|r|l|}
\hline Measurements & \multicolumn{2}{l|}{$\begin{array}{l}\text { Normal } \\
\text { occlusion }\end{array}$} & \multicolumn{2}{l|}{ Study group } & Diff & $\%$ diff & $\begin{array}{l}\text { P value } \\
*\end{array}$ \\
\hline & Mean & SD & Mean & SD & & & \\
\hline Z plane angle & 88.14 & 1.46 & 89.2 & 1.27 & 1.06 & 1.2 & $0.11, \mathrm{~ns}$ \\
\hline Occlusal plane angle & 89.4 & 2.10 & 90.07 & 1.07 & 0.67 & 0.7 & $0.02, \mathrm{~S}$ \\
\hline Antegonial plane angle & 89.79 & 1.31 & 89.3 & 2.1 & -0.49 & -0.5 & $0.37, \mathrm{~ns}$ \\
\hline Antegonial angle & 2.79 & 2.22 & 3.89 & 2.45 & 1.1 & 39.4 & $0.19, \mathrm{~ns}$ \\
\hline
\end{tabular}

Table2. Paired Linear measurements:

\begin{tabular}{|c|c|c|c|c|c|c|c|}
\hline \multirow[t]{2}{*}{ Measurements } & \multicolumn{2}{|c|}{$\begin{array}{l}\text { Normal } \\
\text { occlusion }\end{array}$} & \multicolumn{2}{|c|}{ Study group } & \multirow[t]{2}{*}{ Diff } & \multirow[t]{2}{*}{$\%$ diff } & \multirow[t]{2}{*}{$\begin{array}{l}\text { P value } \\
*\end{array}$} \\
\hline & Mean & SD & Mean & SD & & & \\
\hline $\begin{array}{l}\text { Anterior nasal spine } \\
\text { deviation }\end{array}$ & 1.43 & 1.28 & 1.37 & 1.26 & -0.06 & -4.2 & $0.89, \mathrm{~ns}$ \\
\hline Mandibular deviation & 2.79 & 2.26 & 2.63 & 2.56 & -0.16 & -5.7 & $0.85, \mathrm{~ns}$ \\
\hline $\begin{array}{l}\text { Max. dental midline } \\
\text { deviation }\end{array}$ & 1.57 & 1.79 & 1.26 & 1.66 & -0.31 & -19.7 & $0.62, \mathrm{~ns}$ \\
\hline $\begin{array}{l}\text { Mandibular mid line } \\
\text { deviation }\end{array}$ & 1.71 & 1.94 & 1.89 & 1.82 & 0.18 & 10.5 & $0.79, \mathrm{~ns}$ \\
\hline
\end{tabular}

Table3. Unpaired Linear Measurements:

\begin{tabular}{|l|r|r|r|r|r|r|l|}
\hline & \multicolumn{2}{|l|}{ Normal occlusion } & \multicolumn{2}{l|}{ Study group } & \multicolumn{1}{l|}{ Diff } & \% diff & P value * \\
\hline & Mean & SD & Mean & SD & & & \\
\hline $\begin{array}{l}\text { Frontozygomatic suture to X- } \\
\text { line }\end{array}$ & 1.21 & 1.81 & 1.37 & 1.01 & 0.16 & 13.2 & $0.78, \mathrm{~ns}$ \\
\hline Condylion to X-line distance & 3.86 & 3.03 & 4.89 & 3.56 & 1.03 & 26.6 & $0.37, \mathrm{~ns}$ \\
\hline Zygoma to X-line distance & 3.07 & 2.84 & 7.42 & 4.44 & 4.35 & 14.6 & $0.002, \mathrm{Vs}$ \\
\hline $\begin{array}{l}\text { Pyriform aperture to X-line } \\
\text { distance }\end{array}$ & 2.71 & 1.82 & 3.05 & 2.04 & 0.34 & 12.5 & $0.62, \mathrm{~ns}$ \\
\hline $\begin{array}{l}\text { Maxillary buttress to X-line } \\
\text { distance }\end{array}$ & 3.5 & 2.65 & 4.42 & 3.56 & 0.92 & 26.2 & $0.40, \mathrm{~ns}$ \\
\hline
\end{tabular}


Graph 1.Graphical representation of Paired Linear Measurements:

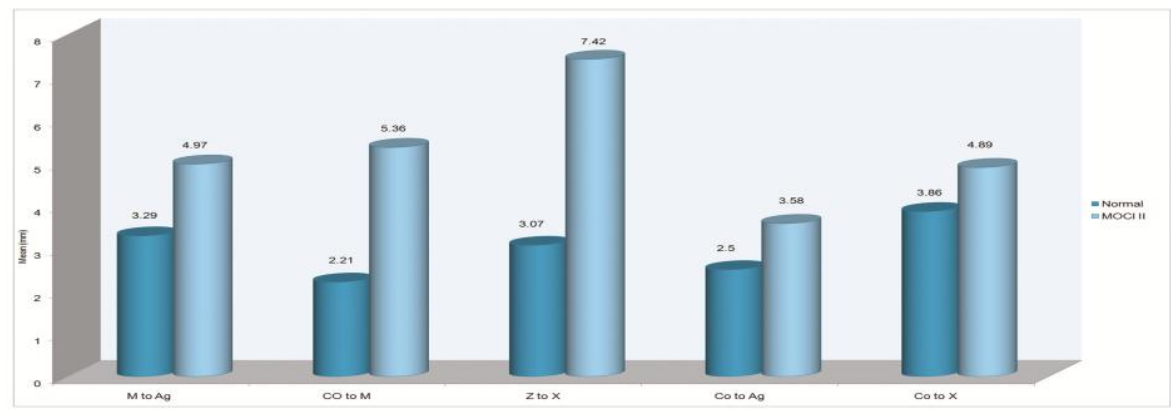

Graph 2. Graphical representation of occlusal plane angle:

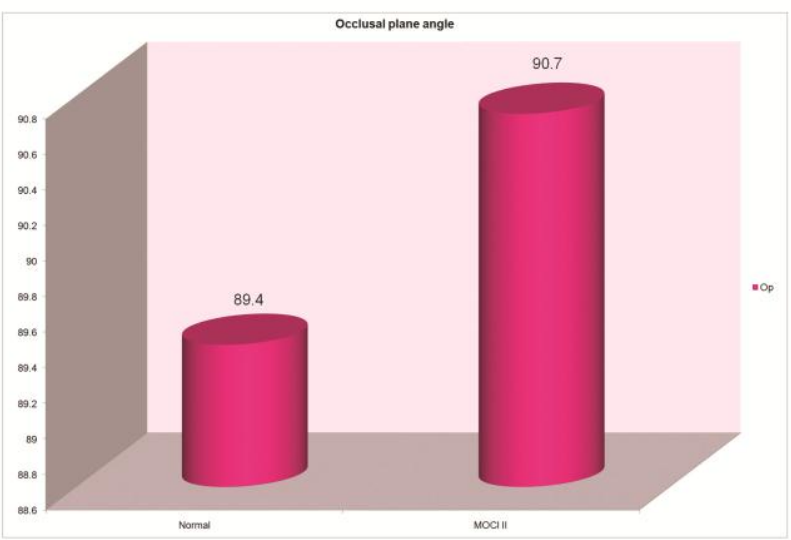

VII. Discussion

As demonstrated by the means and standard deviations, asymmetry of both the dental arches, maxilla, and mandible was a common finding in both normal and malocclusion groups. This result is not unique and has been reported in the literature on numerous occasions. Since the two groups had been originally selected on the basis of dental model characteristics, that is, the relationships of the first permanent molars, it would seem that variables relating to the dental arch should rank highest among the discriminating variables. ${ }^{16} 100 \%$ cases showed facial asymmetry of varying degree.

Class II subdivision cases pose great difficulty in diagnosis and treatment planning ${ }^{3,4}$. The present study has attempted to analyse the degree of facial asymmetry associated with class II subdivision cases. The posteroanterior cephalograms were obtained in centric occlusion for the elimination of postural asymmetries and to ensure accuracy in the evaluation of mandibular asymmetry in relation to the maxilla and the cranial base.

Facial asymmetry was found to be present in both class II subdivision and normal occlusion subjects; however the subdivision group showed significantly greater facial asymmetry. $100 \%$ of class II subdivision cases showed facial asymmetry of varying degree. The occlusal plane angle, Antegonial angle, Condylion to antegonial notch distance and Condylion to menton distance justifies the mandibular asymmetrical appearance in the subjects with subdivision (Fig 5). Studies by Rose et $\mathrm{al}^{6}$ proved shorter ramus on the affected side with a concurrent deviation of the chin and canting of the occlusal plane

It can be observed what has been cited in other studies by Azevedo et $\mathrm{al}^{3}$ - that the asymmetry is mainly in the lower third of the face and that, although we notice asymmetry in the subjects with Class II subdivision, this asymmetry is only slightly different compared with a normal-occlusion group, because these subjects also have some facial asymmetry. Previous studies by $\mathrm{O}^{\prime} B y r n \mathrm{BL}$ et al ${ }^{8}$, Rose et al ${ }^{6}$, have shown mandibular asymmetries along with deviation of chin and canting in occlusal plane,that co-related with this study(fig 6 . Graph 2), and in this study it was found that the condylion to menton distance and occlusal plane angle measurements are significantly different from that in normal occlusion. Craig Michael Minich ${ }^{18}$ has observed a significant mandibular asymmetry was identified between mandibular foramen and mental foramen. The distance was shorter on the Class II side between these two points. 
Williamson and Simmons ${ }^{15}$ found that subjects displaying $3 \mathrm{~mm}$ or more of mandibular asymmetry had a tendency toward a Class II buccal segment occlusion on the short side. This correlates well with the results of the present study. ${ }^{4}$

\section{Clinical Significance}

In view of the above observations, all the patients with class II sub-division should be assessed for asymmetries during clinical examination. Since, all the patients with class II sub-division malocclusion presented with mild asymmetry which is more prominent in lower third of the face along with occlusal cant.

\section{Conclusion}

There was a significant amount of radiographic mandibular asymmetry in relation to Class II subdivision malocclusions in general. As a consequence of the more frequent asymmetry in the lower third of face, the mandibular dental midline and the antegonial angle were deviated on the Class II side, as evaluated on the postero-anterior radiograph. Lower third of face exhibited $10.5 \%$ of asymmetry with angular and $38 \%$ of asymmetry with linear measurements in class II sub-division patients

\section{References}

[1] Go kmen Kurta; Tancan Uysalb; Yildiray Sismanc; Sabri Ilhan Ramoglud. Mandibular Asymmetry in Class II Subdivision Malocclusion. Angle Orthodontist, Vol 78, No 1, 2008

[2] Omer Said Sezgina; Peruze Celenkb; Selim Aricic. Mandibular Asymmetry in Different Occlusion Patterns.-A Radiological Evaluation. Angle Orthodontist, Vol 77, No 5, 2007

[3] Angela Rita Pontes Azevedoa, Guilherme Jansonb, José Fernando Castanha Henriquesc, Marcos Roberto de Freitasb. Evaluation of asymmetries between subjects with Class II subdivision and apparent facial asymmetry and those with normal occlusion. AJODO-2006, vol 129, Number 3.

[4] Turpin DL. Correcting the Class II subdivision malocclusion. Am J Orthod Dentofacial Orthop. 2005; 128(5):555-556.

[5] Alavi DG, Begole EA, Schneider BJ. Proffit WR , Vig KWL , Turvey TA. Facial and dental arch asymmetries in Class II subdivision malocclusion. Am J Orthod Dentofacial Orthop . 1988; 93:38-46

[6] John M. Rose, DDS, Cyril Sadowsky, BDS, MS, Ellen A. BeGole, PhD, and Randall Moles, DDS, MS Chicago. Mandibular skeletal and dental asymmetry in Class II Subdivision malocclusions. AJO-DO Volume 1994 May (489 - 495)

[7] Janson GRP, Metaxas A, Woodside DG, Freitas MR, Pinzan. Three-dimensional evaluation of skeletal and dental asymmetries in Class II subdivision malocclusions. Am J Orthod Dentofacial Orthop . 2001; 119:406-418.

[8] O’Byrn BL. An evaluation of mandibular asymmetry in adults with unilateral posterior cross bite. Am J Orthod Dentofacial Orthop . 1995; 107:394-400

[9] Grummons DC, Van de Coppello MAK. A frontal asymmetry analysis. J Clin Orthod. 1987; 21: $448-465$.

[10] Shah SM, Joshi MR. An assessment of asymmetry in the normal craniofacial complex. Angle Orthod . 1978; 48:141-147.

[11] Fischer B. Asymmetries of the dentofacial complex. Angle Orthod . 1954; 24:179-192.

[12] Janson G, Cruz KS, Woodside DG, Metaxas A, de Freitas MR, Henriques JF. Dentoskeletal treatment changes in Class II subdivision malocclusions in submentovertex and posteroanterior radiographs. Am J Orthod Dentofacial Orthop. 2004 Oct; 126(4):451-63.

[13] Letzer G.M, Kromaj J.H. A posterioanterior cephalometric evaluation of craiofacial asymmetry. Angle Orthod 1967; $37: 205-211$.

[14] Guilherme Janson, a Karina Jerônimo Rodrigues Santiago de Lima,b Donald G. Woodside,c Angelos Metaxas,d Marcos Roberto de Freitas,a and José Fernando Castanha Henriquesa Bauru, São Paulo, Brazil. Class II subdivision malocclusion types and evaluation of their asymmetries. Am J Orthod Dentofacial Orthop 2007;131:57-66.

[15] Eugene H. Williamson, Michael D. Simmons. Mandibular asymmetry and its relation to pain dysfunction. Am J Orthod Dentofacial Orthop. 1979;76:612-7

[16] Debra G. Alavi, D.D.S., \#I\&,* EWn A. Bernard J. St+hnMw, D.D.S., MS. Facial and dental arch asymmetries in Class II subdivision malocclusion Am J Orthod Dentofacial Orthop 1988 Volume 93 Number

[17] Diagnosis of Facial Asymmetry Using Conventional PA Cephalometric Analysis and a Maxillofacial 3-Demensional CT Analysis: A Comparative Study. The Orthodontic Cyber Journal. January 2012.

[18] Craig Michael Minich, D.D.S. An evaluation of skeletal and dental asymmetries in class ii subdivision malocclusions using conebeam computed tomography. An Abstract Presented to the Graduate Faculty of Saint Louis University in Partial Fulfillment of the Requirements for the Degree of Master of Science in Dentistry 2011. 